This is a revised personal version of the text of the final journal article, which is made available for scholarly purposes only, in accordance with the journal's author permissions. The full citation is:

Banks C. J., Zhang Y., Jiang Y., Heaven S. (2012) Trace element requirements for stable food waste digestion at elevated ammonia concentrations. Bioresource Technology 104, 127-135 DOI: 10.1016/j.biortech.2011.10.068

\title{
Trace element requirements for stable food waste digestion at elevated ammonia concentrations
}

\section{Author names and affiliations}

Charles J. Banks ${ }^{1}$, Yue Zhang, Ying Jiang, Sonia Heaven

Faculty of Engineering and the Environment, University of Southampton, Southampton SO17 1BJ, UK

\begin{abstract}
The work investigated why anaerobic digesters treating food waste and operating at high ammonia concentrations suffer from propionic acid accumulation which may result in process failure. The results showed deficiency of selenium, essential for both propionate oxidation and syntrophic hydrogenotrophic methanogenesis, leads to this while supplementation allows operation at substantially higher organic loading rates (OLR). At high loadings cobalt also becomes limiting, due to its role either in acetate oxidation in a reverse Wood-Ljungdahl pathway or in hydrogenotrophic methanogenesis. Population structure analysis using fluorescent in-situ hybridisation showed only hydrogenotrophic methanogens. Critical Se and Co concentrations were established as 0.16 and $0.22 \mathrm{mg} \mathrm{kg}^{-1}$ fresh matter feed at moderate loading. At this dosage the OLR could be raised to $5 \mathrm{~g} \mathrm{VS}^{-1}$ day $^{-1}$ giving specific and volumetric biogas productions of $0.75 \mathrm{~m}^{3} \mathrm{~kg}^{-1} \mathrm{VS}_{\text {added }}$ and $3.75 \mathrm{STP}$ $\mathrm{m}^{3} \mathrm{~m}^{-3}$ day $^{-1}$, representing a significant increase in process performance and operational stability.
\end{abstract}

Keywords: Selenium, cobalt, methanogenesis, food waste, propionic acid accumulation

\section{$1 \quad$ Introduction}

In the anaerobic digestion of domestic food waste a characteristic pattern of volatile fatty acid (VFA) production and accumulation has been observed on a number of occasions and at different scales of operation (Banks and Zhang, 2010; Banks et al., 2008; Climenhaga and Banks 2008; Neiva Correia et al., 2008). When starting from an inoculum of municipal wastewater biosolids digestate, performance is initially good and VFA accumulation only starts after a period of months. This takes the form of an initial increase in acetic acid concentration which reaches a peak then declines, and is then followed by a longer term accumulation of propionic acid. The time span over which these changes occur depends on the process loading, but typically it may be more than a year before the accumulation of acid products overcomes the digester buffering capacity leading to process failure. A theory was

1 * Corresponding author: Tel +44 (0)2380 594650, fax 677519, email cjb@ soton.ac.uk 
put forward to explain this observation (Banks and Zhang, 2010) and the aim of this research was to provide supporting evidence. It was proposed that the peak in acetic acid is a consequence of inhibition of the acetoclastic methanogens as the ammonia concentration reaches a threshold value (Karakashev et al., 2006; Schnurer and Nordberg, 2008). The subsequent decline in acetic acid concentration, despite increasing ammonia concentrations, and its stabilisation at a low value was thought to indicate a shift in the dominant methanogenic activity from acetoclastic to hydrogenotrophic. There is a growing amount of evidence which indicates that this latter group of methanogens have higher tolerance to ammonia (Angelidaki and Ahring, 1993; Hansen et al., 1998; Schnürer and Nordberg, 2008). The non-reversible accumulation of propionic acid was postulated to occur because of a deficiency of the trace elements required for synthesis of the enzymes needed in syntrophic hydrogenotrophic methane production. In particularly selenium (Se), molybdenum (Mo) and tungsten (W) have been reported as important in formate oxidation because of the requirement for them in the enzyme formate dehydrogenase (Böck, 2006). An accumulation of formate, a breakdown product of propionic acid, had been reported as possibly triggering a feedback inhibition in propionic acid oxidation (Dong, 1994).

Both Selenium and Cobalt have been found to be present only at very low concentrations in source segregated domestic food waste collected in the UK and although typically present in inoculum taken from a municipal wastewater biosolids digestion these trace elements would be diluted out of an operational food waste digester over a period of time. The paper presents the results of batch and long-term semi-continuous fed digestion trials carried out with differential supplementation of trace elements, together with results from fluorescent in-situ hybridisation (FISH) analysis to identify the methanogenic groups present at high ammonia concentrations, in support of the above theory.

\section{$2 \quad$ Materials and Methods}

Digesters. Batch tests were carried out in $250 \mathrm{ml}$ conical flasks each provided with a gas sampling bag (Tedlar, SKC Ltd, UK) connected to the flask by a stainless steel tube inserted through a butyl rubber bung. The flasks were maintained at $36 \pm 1{ }^{\circ} \mathrm{C}$ in an orbital shaking incubator operating at $60 \mathrm{rpm}$.

The semi-continuous digesters had a 5-litre capacity with a 4-litre working volume and were constructed of PVC tube with gas-tight top and bottom plates. The top plate was fitted with a gas outlet, a feed port sealed with a rubber bung, and a draught tube liquid seal through which an asymmetric bar stirrer was inserted with a $40 \mathrm{rpm}$ motor mounted directly on the top plate. Temperature was controlled at $36{ }^{\circ} \mathrm{C}$ by circulating water from a thermostatically-controlled bath through a heating coil around the digesters. Semi-continuous operation was achieved by the daily removal of digestate through an outlet port in the base of each digester followed by substrate addition via the feed port. Biogas production was measured using tipping-bucket gas counters with continuous data logging (Walker et al., 2009) and all gas volumes reported are corrected to standard temperature and pressure of $0^{\circ} \mathrm{C}, 101.325 \mathrm{kPa}$.

Food waste. Source segregated food waste from domestic properties delivered to the South Shropshire digestion facility at Ludlow, UK was used in the study. The material was first taken out of biodegradable collection bags and any non-biodegradable contaminants were removed. It was then homogenised using a macerating grinder (S52/010 Waste Disposer, IMC Limited, $\mathrm{UK}$ ), packed into 4-litre plastic storage containers, and frozen at $-18^{\circ} \mathrm{C}$. Before use the frozen feedstock was thawed, and stored at $4^{\circ} \mathrm{C}$ for no more than one week. 
Inoculum. The inoculum used was taken from a laboratory 75-litre (working volume) food waste digester, the previous feedstock and loading history of which are given in detail in Banks and Zhang (2010). In the flask trials the digestate was first sieved through a $1 \mathrm{~mm}$ mesh to remove any large particles, but when used as inoculum for the semi-continuous fed digesters there was no pre-treatment.

\subsection{Batch screening tests}

The batch screening tests were set up as shown in Table 1 . A mix of propionic $\left(8 \mathrm{~g} \mathrm{l}^{-1}\right)$, acetic acid $\left(4.5 \mathrm{~g} \mathrm{l}^{-1}\right)$, glucose $\left(4 \mathrm{~g} \mathrm{l}^{-1}\right)$ starch $\left(4 \mathrm{~g} \mathrm{l}^{-1}\right)$ and ammonia $\left(2 \mathrm{~g} \mathrm{l}^{-1}\right)$ was added to the sieved digestate to provide both fermentation and test substrates.

Trace element (TE) supplementation concentrations were chosen based on the results from previous trials, and on baseline concentrations in the test digestate. The dose was chosen to avoid reaching toxic concentrations of the trace element concerned. The tests were carried out in duplicate, with $200 \mathrm{ml}$ of supplemented digestate in each flask together with the trace element mix. The headspace of each flask was purged with a gas mixture of $\mathrm{N}_{2}$ and $\mathrm{CO}_{2}$ (80:20) and then connected to the gas sampling bag. Each flask was sampled and analysed at fixed intervals. A set of duplicate flasks containing a more comprehensive trace element mix of $\mathrm{Al}\left(0.1 \mathrm{mg} \mathrm{l}^{-1}\right), \mathrm{B}\left(1 \mathrm{mg} \mathrm{l}^{-1}\right), \mathrm{Co}\left(1.0 \mathrm{mg} \mathrm{l}^{-1}\right), \mathrm{Cu}\left(0.1 \mathrm{mg} \mathrm{l}^{-1}\right), \mathrm{Fe}\left(5.0 \mathrm{mg} \mathrm{l}^{-1}\right), \mathrm{Mn}\left(1.0 \mathrm{mg} \mathrm{l}^{-}\right.$ $\left.{ }^{1}\right)$, Mo $\left(0.2 \mathrm{mg} \mathrm{l}^{-1}\right)$, Ni $\left(1.0 \mathrm{mg} \mathrm{l}^{-1}\right)$, Se $\left(0.2 \mathrm{mg} \mathrm{l}^{-1}\right)$, W $\left(0.2 \mathrm{mg} \mathrm{l}^{-1}\right)$, and $\mathrm{Zn}\left(0.2 \mathrm{mg} \mathrm{l}^{-1}\right)$ was also set up.

\subsection{Semi-continuous digestion trials}

Six pairs of digesters were used and were supplemented as shown in Figure 1 with 1) Se and Mo; 2) Se, Mo, Co and W; 3) Se, Mo, So, W, Fe and Ni; 4) Se, Mo, Co, W, Fe, Ni, Zn, Cu, $\mathrm{Mn}, \mathrm{Al}, \mathrm{B}$; 5) No trace element addition (control); and 6) No trace element addition (control). The two pairs of controls were run to test independently the impact of increasing the food waste load on the digesters, irrespective of trace element additions. At the start of the experiment the digesters were each inoculated with 3.5 litres of digestate and were then operated at an organic loading rate (OLR) of $1.6 \mathrm{~kg} \mathrm{VS} \mathrm{m}^{-3} \mathrm{day}^{-1}$ without any digestate removal, until they reached a working volume of 4 litres. At this point (day 1) the digesters receiving supplementation were given an initial trace element dose as shown in Table 2; the trace element concentrations in the digestate before supplementation are also shown in Table 2 .

The OLR in all digesters was raised to $2.0 \mathrm{~kg} \mathrm{VS} \mathrm{m}^{-3}$ day $^{-1}$ on day 1 ; subsequent changes in loading and in the pattern of trace element supplementation are presented in Figure 1. Food waste was added each day to give the desired OLR and digestate was removed once per week to maintain a working volume of 4.0 litres, without recirculation of liquor or fibre. The retention time was therefore determined by the volatile solids content of the food waste, and was around 95, 63, 48, and 38 days at an OLR of 2, 3, 4, and $5 \mathrm{~kg} \mathrm{VS} \mathrm{m}^{-3}$ day $^{-1}$ respectively. Trace element additions were made weekly. The amount added was equal to that required for the wet weight of food waste added to the digester each week; this calculation did not take into account any additional trace element input arising from the food waste itself.

\subsection{Analytical methods}

Total solids (TS) and volatile solids (VS) were measured using Standard Method $2540 \mathrm{G}$ (APHA, 2005). pH was determined using a Jenway 3010 meter (Bibby Scientific Ltd, UK) with a combination glass electrode calibrated in buffers at $\mathrm{pH} \mathrm{4,7}$ and 9.2 (Fisher Scientific, 
UK). Alkalinity was measured by titration with $0.25 \mathrm{~N} \mathrm{H}_{2} \mathrm{SO}_{4}$ to endpoints of $\mathrm{pH} 5.75$ and 4.3, allowing calculation of total (TA), partial (PA) and intermediate alkalinity (IA) (Ripley et al., 1986). Total Kjeldahl Nitrogen (TKN) was determined using a Kjeltech block digester and ammonia by steam distillation unit according to the manufacturer's instructions (Foss Ltd, Warrington, UK). Volatile fatty acids (VFA) were quantified in a Shimazdu GC-2010 gas chromatograph (Shimadzu, Milton Keynes, UK), using a flame ionization detector and a capillary column type SGE BP-21. Biogas composition $\left(\mathrm{CH}_{4}\right.$ and $\left.\mathrm{CO}_{2}\right)$ was determined using a Varian star $3400 \mathrm{CX}$ Gas Chromatograph, calibrated with $65 \%(\mathrm{v} / \mathrm{v}) \mathrm{CH}_{4}$ and $35 \%(\mathrm{v} / \mathrm{v})$ $\mathrm{CO}_{2}$. Trace element concentrations were determined using ICP-MS or ICP-OES at a commercial laboratory Severn Trent Services (Coventry, UK) after in-house hydrochloric nitric acid digestion (SCA, 1986).

Fluorescent in situ hybridisation. All the digesters were sampled on day 316 for microbial community structure analysis using the Fluorescent In-Situ Hybridisation (FISH) technique. Density gradient centrifugation with Nycodenz (Sigma-Aldrich, UK) was used before performing the analysis to separate the microbial biomass in the digestate from other components including both partially digested input material and the non-digestable components of the food waste. The procedure for density gradient centrifugation was adapted from previous studies (Caracciolo et al., 2005). $10 \mathrm{ml}$ of digestate was mixed with $90 \mathrm{ml}$ of $1 \times$ phosphate buffer saline (PBS) solution in a Waring blender for 1 minute. $\mathrm{N}_{2} / \mathrm{CO}_{2}(80 / 20)$ gas was purged into the blender during the mixing. $1 \mathrm{ml}$ of this diluted digestate was transferred into a 2-ml centrifuge tube, and then $1 \mathrm{ml}$ of Nycodenz solution with a density of $1.2 \mathrm{~g} \mathrm{ml}^{-1}$ was gently injected to the bottom of the centrifuge tubes using needle and syringe. After centrifugation at $20000 \mathrm{~g}$ for 30 minutes, the microbial biomass suspended in the liquid layers was collected using a needle and syringe, and then washed twice using $1 \times$ PBS solution.

The separated microbial biomass was then fixed with $4 \%$ of paraformaldehyde (SigmaAldrich, UK) solution and used for FISH analysis (Daims, 2005). The oligonucleotide probes (Thermo Electron Biopolymers, Ulm, Germany), as detailed in Table 3, and the hybridisation stringency were chosen based on a previous study (Karakashev et al., 2006). Hybridised samples were viewed using a Leica TCS SP2 confocal laser scanning microscopy, and 20 different microscrope fields were randomly selected for each hybridisation treatment. The laser wavelength to excite the fluorochrome dyes 6-Fam, Cy3, and Cy5 was 488nm, 561nm, and $633 \mathrm{~nm}$, respectively.

\section{$3 \quad$ Results and discussion}

\subsection{Batch screening tests}

Figure 2 shows a selection of VFA degradation profiles from the flask trials illustrating the differences observed between different supplementations. It is clear from the results that $\mathrm{Se}$ and Mo were able to reduce the time required for degradation of both acetic and propionic acid compared with that in the controls or in the flasks supplemented with $\mathrm{Ni}$ and Fe only. The flasks containing Co and $\mathrm{W}$ showed some reduction in degradation time, but the effect was not as great as that either in the Se and Mo flasks or in the flasks dosed with a full complement of trace elements including Se and Mo.

Using the average from duplicate flasks for the maximum acetic or propionic acid degradation rate a statistical analysis was carried out using the SAS software package. The results showed that only selenium (Se) significantly improved the acetic acid degradation, with a p-value of 0.0012; and Se, Mo, and the mix of Co and W had a significant effect on 
propionic acid degradation, with p-values of $0.0077,0.026$, and 0.033 respectively. Although Figure 2 indicated a moderate positive influence of $\mathrm{Co}$ and $\mathrm{W}$ on propionic acid degradation, the experimental design did not allow this to be statistically analysed because the 2-factor interaction of ' $\mathrm{Co}$ and $\mathrm{W}$ ' is confounded with ' $\mathrm{Ni}$ and $\mathrm{Fe}$ ' and 'Mo and Se' in this quarterfraction of $2 \mathrm{IV}^{6-2}$ design. The results were in agreement with the proposed theory that the inoculum microbial consortium which had been exposed to high ammonia concentrations had a requirement for these elements.

\subsection{Semi-continuous digestion}

The semi-continuous digesters were fed over a period of 520 days on source segregated food waste. Feedstock and inoculum characteristics are shown in Table 4.

Specific and volumetric biogas production rates for all the digesters are shown in Figure 3. The control digesters which were initially fed at an OLR of $2 \mathrm{~g} \mathrm{VS}^{-1} \mathrm{day}^{-1}$ showed relatively consistent specific biogas production (SBP) over the trial period. This fluctuated around 0.7 STP $\mathrm{m}^{3} \mathrm{~kg}^{-1} \mathrm{VS}_{\text {added }}$, although in order to maintain both this yield and the stability of the digestion as indicated by other monitoring parameters the OLR had to be gradually reduced (Figure 1). The control digesters in which the OLR was increased to $3 \mathrm{~g} \mathrm{VS}^{-1} \mathrm{day}^{-1}$ showed a decline in biogas production following the loading increase, and feeding was stopped on day 120. The SBP in the digesters receiving trace element supplementation fluctuated around 0.75 STP $\mathrm{m}^{3} \mathrm{~kg}^{-1} \mathrm{VS}_{\text {added, }}$, with no apparent deterioration in this yield as the OLR increased. The volumetric biogas production (VBP) reflected changes in the OLR applied to the digesters, with a small reduction in the lower-loaded controls as the loading was gradually decreased. In the trace element (TE) supplemented digesters VBP increased from around $1.5 \mathrm{~m}^{3} \mathrm{~m}^{-3} \mathrm{day}^{-1}$ to around $3.75 \mathrm{~m}^{3} \mathrm{~m}^{-3}$ day $^{-1}$ at the highest loading of $5 \mathrm{~g} \mathrm{VS} \mathrm{l}^{-1}$ day $^{-1}$.

From day 112 TE supplementation was stopped in one digester of the pair originally supplemented with $\mathrm{Se}, \mathrm{Mo}, \mathrm{Co}, \mathrm{W}, \mathrm{Fe}$ and $\mathrm{Ni}$; feeding of both digesters continued at an OLR of $3 \mathrm{~g} \mathrm{VS} \mathrm{l}^{-1} \mathrm{day}^{-1}$. The digester from which TE supplementation was withdrawn began to show deterioration in both SBP and VBP between days 350 and 400, corresponding to the time necessary for washout of the trace elements that had been previously supplemented.

Other digestion performance parameters are shown in Figure 4. The $\mathrm{pH}$ of the control digesters in which the loading was increased had declined to less than 7 by the time that feeding ceased. This decline is reflected in the change in the ratio of intermediate alkalinity:partial alkalinity (IA:PA), which climbed to around 2.75 , indicating both the accumulation of volatile fatty acids and the development of digestion instability (Ripley et al., 1986). The $\mathrm{pH}$ in the lower loaded controls showed a gradual decline over the trial period and a corresponding increase in the IA:PA ratio, despite the reduction in loading. The $\mathrm{pH}$ in the digesters receiving TE supplements remained around 8 over the trial period, and the IA:PA ratio in these digesters remained below 0.5. The exception was the digester from which trace element supplementation was removed. In this digester the IA:PA ratio was seen to increase slightly from day 300 , and then reduced slightly when a single dose of Se was accidently added on day 315 . The ratio rose after this event, peaking at about day 390; and then fell again when trace element supplementation to this digester was deliberately resumed on day 427.

The total ammonia nitrogen (TAN) concentration in the digesters at the start of the trial was around $5 \mathrm{~g} \mathrm{l}^{-1}$ and in the control digester this gradually increased to a maximum of $6.1 \mathrm{~g} \mathrm{l}^{-1}$; a similar increase was seen in the digester from which TE supplementation was removed. TAN 
in the TE supplemented digesters showed an initial increase until the loading rate increased from 4 to $5 \mathrm{~g} \mathrm{VS}^{-1} \mathrm{day}^{-1}$, at which point there was a small drop in concentration which then stabilised at around $5.4 \mathrm{~g} \mathrm{l}^{-1}$. Interestingly the TAN concentration in the digester from which supplements were removed also dropped when supplementation was resumed. The reasons for the reduced TAN concentration in the TE supplemented digester are unknown, although Lindorfer et al. (2011) have recently shown a relationship between trace element supplementation and biological fixed nitrogen which may represent increased microbial biomass in the digestate. There was also a $3 \%$ difference in the biogas methane percentage between the control digesters at 55\% compared to $58 \%$ for those supplemented with TE.

Figure 5 shows the total VFA profile in the digesters and provides some explanations for changes seen in the other digestion performance indicators. The inoculum was already acclimated to food waste, having previously been fed on the same source segregated material in a 75-litre working capacity digester for a period of over a year, albeit at a low OLR. The digesters to which TE supplements were added showed a rapid reduction in the VFA that was already present in the inoculum digestate. The non-supplemented controls showed an initial increase in VFA corresponding to the load increase. This was much more severe in the control in which the load was gradually increased to $3 \mathrm{~g} \mathrm{VS}^{-1} \mathrm{day}^{-1}$, and when feeding stopped on day 120 the total VFA concentration in this digester had risen to more than 30000 $\mathrm{mg} \mathrm{l}^{-1}$. The lower loaded control which maintained good SBP showed a gradual increase in total VFA concentration over a 400-day period, which reached $24000 \mathrm{mg} \mathrm{l}^{-1}$ before falling slightly and stabilising at around $20000 \mathrm{mg} \mathrm{l}^{-1}$. In both cases the increase in VFA corresponded to changes in the IA:PA ratio, providing further support for the monitoring of this ratio as a rapid and reliable indicator of the onset of digester instability due to VFA accumulation.

In the digesters supplemented with TE it appeared that a combination of Se and Mo was sufficient to prevent VFA accumulation, as VFA concentrations remained low even when the loading was increased. It was not until shortly after an increase in OLR to $5 \mathrm{~g} \mathrm{VS}^{-1}$ day $^{-1}$ that VFA started to accumulate in the Se and Mo supplemented digester. It was initially hypothesised that this might be due to increasing demand placed on the Se-containing enzyme systems as the OLR was increased, resulting in increased growth rate and metabolic activity. To test this, the Se dose was increased on day 329; but no reduction in VFA was observed, suggesting that at the higher load some other component had become limiting. Total VFA concentrations in this digester were therefore allowed to accumulate to around $12000 \mathrm{mg} \mathrm{l}^{-1}$ before the Se dose was reduced and a supplement of Co was added. This resulted in a rapid fall in VFA concentrations to values of $<500 \mathrm{mg} \mathrm{l}^{-1}$.

In the digester maintained at an OLR of $3 \mathrm{~g} \mathrm{VS}^{-1} \mathrm{day}^{-1}$ and to which TE supplementation ceased on day 112, VFA were seen to start accumulating around day 280, and had reached a concentration of about $4000 \mathrm{mg}^{-1}$ when a one-off dose of $0.12 \mathrm{mg}$ Se was accidently added, equivalent to increasing the concentration of Se in the digesters by $0.03 \mathrm{mg} \mathrm{l}^{-1}$. The very rapid reduction in accumulated VFA observed after this event was confirmed by improvement in the IA:PA ratio. The improvement was short-lived, but this response suggests that at a loading of $3 \mathrm{~g} \mathrm{VS} \mathrm{l}^{-1}$ day $^{-1}$ trace elements other than Se were present in adequate concentrations to maintain stable methanogenesis. When the VFA concentration had reached $10,000 \mathrm{mg} \mathrm{l}^{-1}$ the digester was supplemented with $\mathrm{Se}$, Co and $\mathrm{Ni}$, which rapidly reduced the VFA to $<500 \mathrm{mg} \mathrm{l}^{-1}$. 
The digesters receiving multiple TE supplements including Se and Co as part of the mix showed stable digestion throughout the trial period, with VFA concentrations never exceeding $500 \mathrm{mg} \mathrm{l}^{-1}$. A trace element supplementation experiment by Feng et al. (2010) using a central composite design on digesters receiving industrial food wastes found that addition of Se and $\mathrm{W}$ increased methane yield as well as maintaining low VFA concentrations. No additional requirement for Co was found at the OLR used, and it may be that this is necessary only at higher loadings, as in the present study. Their research also indicated that supplementation with $\mathrm{Ni}, \mathrm{B}$ or Mo was not essential, in agreement with the current work where food waste was considered to have sufficient concentration of these elements.

Figure 6a shows the dilute-out curve for the digester in which TE supplementation ceased on day 112. This was modelled assuming the digester to be a continuously stirred tank reactor (CSTR) with a hydraulic retention time calculated from the working volume and the wet weight of food waste added each day (assuming a density of $1 \mathrm{~kg} \mathrm{l}^{-1}$ ). Digestate samples were taken for TE analysis over this time and the results for Se and Co are plotted in Figure 6a, showing good agreement with calculated values. The total VFA concentration is shown on the same graph, and the limiting concentrations of the two elements are taken to be at the intersection of the TE washout and VFA concentration curves. Based on this the required concentrations of Se and Co were estimated to be 0.16 and $0.22 \mathrm{mg} \mathrm{kg}^{-1}$ fresh matter feed material at moderate loading; these concentrations may need to be increased at higher loadings.

The concentrations of both Se and Co in the food waste used as substrate in the trials was below these critical thresholds. These values would also account for the high VFA concentrations that have been observed in a full-scale digester treating food waste from the same source (Banks and Zhang, 2010) and in earlier pilot-scale and laboratory trials (Banks et al, 2008; Climenhaga and Banks 2008). There was no evidence that either W or Mo were required in concentrations greater that those found in the food waste.

Methanogenic diversity in digester samples. The FISH analysis showed that the methanogenic groups in both control digesters and in all the digesters with trace element supplementation were members of the order Methanoimicrobiales, indicating that the dominant metabolic pathway of food waste digestion was via syntrophic acetate oxidation and hydrogenotropic methanogenesis. This supported the hypothesis that syntrophic acetate oxidation is the main mechanism for acetate degradation at ammonia concentrations above a threshold value. Very few studies have considered the population structure in food waste digesters, and only the work of Feng et al. (2010) has looked at how trace element additions may affect this. The digester ammonia concentrations in their study, however, were between $2.3-3 \mathrm{~g} \mathrm{~N}^{-1}$ which is lower than those found in the present work. This, coupled with the lower $\mathrm{pH}$ in the digesters, makes it likely that free ammonia concentrations were below the toxicity threshold for acetoclastic methanogens (Schnurer and Nordberg, 2008). Analysis of the microbial population using a combination of genetic techniques showed acetoclastic methanogens to be present, indicating that this route may still have been operating and thus potentially offering support to the current work.

The above results show that Se is an essential trace element in food waste digestion. This requirement provides circumstantial evidence to support the original hypothesis that under high ammonia concentrations hydrogenotrophic methanogenesis may be the principle route to methane formation. This was confirmed by the results from the FISH analysis that showed 
that by day 316 no acetoclastic methanogens could be identified in samples from any of the digesters; by this time the ammonia concentration was above $5000 \mathrm{mg}^{-1}$ in all digesters. The results also confirmed previous observations that in food waste digesters without trace element supplementation an accumulation of VFA occurs, and the main component in this accumulation is propionic acid, as can be seen in the VFA profile of the lower loaded control digester (Figure 6b). The VFA profile showed that initially acetic acid was predominant, with propionic acid and longer chain length VFA are at low concentrations as expected. The buildup of propionate can be seen from around day 100 and from that time becomes the predominant VFA.

The non-reversible accumulation of propionic acid was postulated to occur because of a deficiency of the trace elements required for synthesis of the enzymes needed in syntrophic hydrogenotrophic methane production, particularly the formate dehydrogenase required for formate oxidation. The experimental results do not, however, conclusively prove this original hypothesis as the oxidation of propionic acid, with its uneven carbon chain length, produces a mixed product of acetate, $\mathrm{CO}_{2}, \mathrm{H}_{2}$ and formate (Mueller et al., 2010), with side-reactions to produce butyrate and higher-chain fatty acids (de Bok et al., 2001; Stams et al., 1998). The enzymes required for propionic acid oxidation may themselves require the trace elements Se, Mo, and W (de Bok et al., 2003; Mueller et al., 2010; Worm et al., 2011). It has long been recognised, however, that the syntrophic degradation of propionate can be inhibited by a product-induced feedback inhibition (Dong, 1994; Fukuzaki et al., 1990; Kus and Wiesmann, 1995). The experimental results presented suggest that in this particular case it is unlikely to be triggered by $\mathrm{H}_{2}$. The maximum partial pressures of $\mathrm{H}_{2}$ under which syntrophic propionate and acetate oxidisation can take place are in the same range (Schink, 1997) and as there is no accumulation of acetate its oxidation does not appear to be inhibited. It is possible that formate is the trigger for inhibition, but the concentration range at which this occurs has rarely been studied (Schink, 1997), whereas the partial pressure at which $\mathrm{H}_{2}$ has an effect is well known (Cord-Ruwisch et al., 1997). Although most microorganisms involved in interspecies electron transfer can exchange hydrogen with formate and vice versa, and the standard redox potential of both electron carrier systems $\left(\mathrm{H}^{+} / \mathrm{H}_{2}\right.$ and $\mathrm{CO}_{2} /$ formate $)$ is nearly identical (Thauer et al., 2008), the conversion between them requires formate dehydrogenase (FDH) which has been reported to require Se, Mo and W (Andreesen and Ljungdahl, 1973; de Bok et al., 2003; Worm et al., 2011). The results presented cannot confirm that the Selenium was exclusively required for this enzyme system, but it is clearly vital to the proper functioning of this pathway. Oxyanions are also required for formyl-methanofuran dehydrogenase, and Se for hydrogenase and heterodisulfide reductase (Müller, 2003; Thauer et al., 2008; Stock and Rother, 2009; Zhu and Tan, 2009).

The trace elements requirement for syntrophic hydrogenotrophic methanogenesis is quite different to that required when the acetoclastic methanogenic pathway is predominant. When this is the case $\mathrm{Co}, \mathrm{Ni}, \mathrm{Fe}$ are essential in the formation of $\mathrm{CO}$ dehydrogenase, acetyl-CoA decarbonylase, Methyl-H $\mathrm{H}_{4}$ SPT:HS-CoM methyltransferase, Methyl-CoM reductase and other enzymes (Ferry, 1992; Kida et al., 2001). These three cations, however, remain essential in the syntrophic acetate oxidisation by the reverse Wood-Ljungdahl pathway and the hydrogenotrophic route (Thauer et al., 2008; Zhu and Tan, 2009. At the lower loadings there appear to be sufficient trace elements to supply the needs of the enzymes in this pathway; but it is clear that at the higher loading used in these experiments cobalt also becomes limiting, although this was not apparent until around day 280. 
It can be seen that once coupled syntrophic acetate oxidisation and hydrogenotrophic methangenesis are established in a non-competitive environment with the necessary trace element supplementation then concentrations of all species of VFA can remain low.

Supplementation with Se and Co allowed the OLR on the system to be increased to $5 \mathrm{~g} \mathrm{VS}^{-1}$ day $^{-1}$ resulting in a higher specific methane yield and almost three times the volumetric biogas production. In terms of a commercial digester treating food waste, this represents a significant enhancement in performance as well as a reduced risk of process failure due to accumulation of VFA.

\section{Conclusions}

The work did not fully elucidate the metabolic pathways for methane formation in food waste digesters, but showed that acetate oxidation was the main route. Identification of methanogenic groups showed loss of acetoclastic methanogens. In non-supplemented digesters VFA accumulation indicated inhibition of either propionate oxidising bacteria or formate reducing hydrogenotrophic methanogens, resulting in loss of syntrophic interspecies electron transfer. In either case propionic acid will accumulate. The work clearly demonstrated that both selenium and cobalt could prevent this, and are required for interspecies electron transfer at high ammonia concentrations. Supplementation allowed stable operation at higher OLR with enhanced performance efficiency.

\section{Acknowledgements}

The authors wish to thank the UK Government's Department of the Environment Food and Rural Affairs (Defra) and the European Union 7th Framework programme for financial support to carry out this work through grant numbers WR1208 and 241334 (VALORGAS) respectively. Thanks are also due to BiogenGreenfinch Ltd for providing food waste.

\section{References}

Andreesen, J.R. and Ljungdahl, L.G., 1973. Formate dehydrogenase of Clostridium Thermoaceticum: incorporation of selenium-75, and effects of selenite, molybdate, and tungstate on enzyme. J. Bacteriol. 116(2), 867-873.

Angelidaki, I. and Ahring, B. K., 1993. Thermophilic anaerobic digestion of livestock waste: the effect of ammonia. Appl. Microbiol. Biot. 38, 560-564.

APHA, 2005. Standard Methods for the Examination of Water and Wastewater, $21^{\text {st }}$ ed. American Public Health Association, American Water Works Association, Water Environment Federation, Washington, USA.

Banks C.J., Chesshire, M. and Stringfellow A., 2008. A pilot-scale comparison of mesophilic and thermophilic digestion of source segregated domestic food waste. Wat. Sci. Technol. 58(7), 1475-1480.

Banks, C J., Chesshire, M., Heaven, S. and Arnold R., 2011. Anaerobic digestion of sourcesegregated domestic food waste: Performance assessment by mass and energy balance. Bioresource Technol. 102(2), 612-620.

Banks C.J. and Zhang, Y., 2010. Technical Report: Optimising inputs and outputs from anaerobic digestion processes. Defra Project Code WR0212. Department of the Environment, Food and Rural Affairs. http://randd.defra.gov.uk/Document.aspx?Document=WR0212_8890_FRP.pdf

Böck, A. 2006. Selenium Proteins Containing Selenocysteine. Encyclopedia of Inorganic Chemistry. John Wiley \& Sons, Published online: DOI: 10.1002/0470862106.ia215 
Caracciolo, A.B., Grenni, P., Cupo, C. and Rossetti, S., 2005. In situ analysis of native microbial communities in complex samples with high particulate loads. FEMS Microbiol. Lett. 253, 55-58.

Climenhaga, M.A. and Banks C.J., 2008. Anaerobic digestion of catering wastes: effect of micronutrients and retention time. Wat. Sci. Technol. 57(5), 687-692.

Cord-Ruwisch R., Mercz T.I., Hoh C.Y. and Strong G.E., 1997. Dissolved hydrogen concentration as an on-line control parameter for the automated operation and optimization of anaerobic digesters. Biotechnol. Bioeng. 56(6), 626-634.

Daims H., Stoecker K. and Wagner M., 2005. Fluorescence in situ hybridization for the detection of prokaryotes. Advanced Methods in Molecular Microbial Ecology. Osborn A. M. and Smith C. J. Abingdon, Bios-Garland: 213-239.

de Bok F.A.M., Stams A.J.M., Dijkema C. and Boone D.R., 2001. Pathway of propionate oxidation by a syntrophic culture of Smithella propionica and Methanospirillum hungatei Appl. Environ. Microb. 67(4), 1800-1804.

de Bok F.A.M., Hagedoorn P.L., Silva P.J., Hagen W.R., Schiltz E., Fritsche K. and Stams A.J.M., 2003. Two W-containing formate dehydrogenases (CO2-reductases) involved in syntrophic propionate oxidation by Syntrophobacter fumaroxidans. Eur. J. Biochem. 270(11), 2476-2485.

Dong X., Plugge C.M. and Stams A.J.M., 1994. Anaerobic degradation of propionate by a mesophilic acetogenic bacterium in coculture and triculture with different methanogens. Appl. Environ. Microb. 60(8), 2834-2838.

Feng, X.M., Karlsson, A., Svensson, B.H., Bertilsson, S., 2010, Impact of trace element addition on biogas production from food industrial waste - Linking process to microbial communities, FEMS Microbiol. Ecol. 74 (1), 226-240.

Ferry, J. G. (1992) Methane from acetate. J. Bacteriol. 174(17), 5489-5495.

Fukuzaki S., Nishio N., Shobayashi M. and Nagai S., 1990. Inhibition of the fermentation of propionate to methane by hydrogen, acetate, and propionate. Appl. Environ. Microbiol. 56(3), 719-723.

Hansen, K.H., Angelidaki, I. and Ahring, B.K., 1998. Anaerobic digestion of swine manure: Inhibition by ammonia. Water Res. 32(1), 5-12.

Karakashev D., Batstone D. J., Trably E. and Angelidaki I., 2006. Acetate oxidation is the dominant methanogenic pathway from acetate in the absence of Methanosaetaceae. Appl. Environ. Microbiol. 72(7), 5138-5141.

Kida, K., Shigematsu, T., Kijima, J., Numaguchi, M., Mochinaga, Y., Abe, N. and Morimura, S., 2001. Influence of $\mathrm{Ni}^{2+}$ and $\mathrm{Co}^{2+}$ on methanogenic activity and the amounts of coenzymes involved in methanogenesis. J. Biosci. Bioeng. 91(6), 590-595.

Kus, F. and Wiesmann, U., 1995. Degradation kinetics of acetate and propionate by immobilized anaerobic mixed cultures. Water Res. 29(6), 1437-1443.

Lindorfer, H., Ramhold, D., Frauz, B. 2011. Nutrient and trace element supply in AD plants and effect of trace element application. Proc. International IWA Symposium on Anaerobic Digestion of Solid Wastes and Energy Crops, Vienna 28 August - 1 September 2011.

Mueller, N., Worm, P., Schink, B., Stams, A.J.M. and Plugge C.M., 2010. Syntrophic butyrate and propionate oxidation processes: from genomes to reaction mechanisms Environmental Microbiology Reports 2(4), 489-499.

Müller, V., 2003. Energy conservation in acetogenic bacteria. Appl. Environ. Microbiol. 69(11), 6345-6353.

Neiva Correia, C., Vaz, F., Torres, A., 2008. Anaerobic digestion of biodegradable waste operational and stability parameters for stability control. 5th IWA Int Symp on AD of Solid Wastes \& Energy Crops, Tunisia. 
Ripley, L.E., Boyle, W.C. and Converse, J.C. (1986) Improved alkalimetric monitoring for anaerobic digestion of high-strength wastes. Journal Water Pollution Control Federation 58(5), 406-411.

SCA, 1986. Methods for the determination of metals in soils, sediments and sewage sludge and plants by hydrochloric-nitric acid digestion. Methods for the Examination of Waters and Associated Materials, Standing Committee of Analysts. HMSO, London.

Schink, B., 1997. Energetics of syntrophic cooperation in methanogenic degradation. Microbiol. Mol. Biol. R. 61 (2), 262-280.

Schnurer, A. and Nordberg, A., 2008. Ammonia, a selective agent for methane production by syntrophic acetate oxidation at mesophilic temperature. Wat. Sci. Technol. 57(5), 735-740.

Stams A.J.M., Dijkema C., Plugge C.M. and Lens, P., 1998. Contribution of (13)C-NMR spectroscopy to the elucidation of pathways of propionate formation and degradation in methanogenic environments. Biodegradation 9(6): 463-473.

Stock, T. and Rother, M. 2009. Selenoproteins in Archaea and Gram-positive bacteria. BBAGeneral 1790, 1520-1232.

Thauer R.K., Kaster A.-K., Seedorf H., Buckel W. and Hedderich, R., 2008. Methanogenic archaea: ecologically relevant differences in energy conservation. Nat. Rev. Microbiol. 6(8), 579-591.

Walker, M., Zhang, Y., Heaven, S., Banks, C.J., 2009. Potential Errors in the Quantitative Evaluation of Biogas Production in Anaerobic Digestion Processes. Bioresource Technol. 100(24), 6339-6346

Worm, P., Fermoso, F.G., Stams A.J.M., Lens P.N.L. and Plugge C.M., 2011. Transcription of fdh and hyd in Syntrophobacter spp. and Methanospirillum spp. as a diagnostic tool for monitoring anaerobic sludge deprived of molybdenum, tungsten and selenium. Environ. Microbiol. 13(5), 1228-1235.

Zhu X. and Tan X. (2009) Metalloproteins/metalloenzymes for the synthesis of acetyl-CoA in the Wood-Ljungdahl pathway. Science in China Series B-Chemistry 52(12): 2071-2082.

Table 1. Design of the flask trial and concentrations of TE added and that present in the inoculum used

\begin{tabular}{lllllll}
\hline & $\mathbf{C o}$ & $\mathbf{S e}$ & $\mathbf{W}$ & $\mathbf{M o}$ & $\mathbf{N i}$ & $\mathbf{F e}$ \\
\hline $\begin{array}{l}\text { Trace element } \\
\text { compound used }\end{array}$ & $\begin{array}{l}\mathrm{CoCl}_{2} \cdot \\
6 \mathrm{H}_{2} \mathrm{O}\end{array}$ & $\mathrm{Na}_{2} \mathrm{SeO}_{3}$ & $\begin{array}{l}\mathrm{Na}_{2} \mathrm{WO}_{4} \cdot \\
2 \mathrm{H}_{2} \mathrm{O}\end{array}$ & $\begin{array}{l}\left(\mathrm{NH}_{4}\right)_{6} \mathrm{Mo}_{7} \mathrm{O}_{24} \\
-4 \mathrm{H}_{2} \mathrm{O}\end{array}$ & $\begin{array}{l}\mathrm{NiCl}_{2} \cdot 6 \mathrm{H}_{2} \\
\mathrm{O}\end{array}$ & $\mathrm{FeCl}_{2} \cdot 4 \mathrm{H}_{2} \mathrm{O}$ \\
\hline $\begin{array}{l}\text { Concentration added } \\
\text { (as trace element) }\end{array}$ & & & & & & \\
$\mathrm{mg} \mathrm{l}^{-1}$ & 1.0 & 0.2 & 0.2 & 0.2 & 1.0 & 5.0 \\
\hline $\begin{array}{l}\text { Initial concentration } \\
\text { in inoculum mg 1 1 }\end{array}$ & 0.083 & 0.050 & 0.035 & 0.29 & 2.9 & 173.7 \\
\hline 1 & - & - & - & - & - & - \\
2 & - & $\mathrm{Se}$ & $\mathrm{W}$ & - & - & $\mathrm{Fe}$ \\
3 & - & - & $\mathrm{W}$ & $\mathrm{Mo}$ & - & $\mathrm{Fe}$ \\
4 & - & $\mathrm{Se}$ & - & $\mathrm{Mo}$ & - & - \\
5 & - & - & - & - & $\mathrm{Ni}$ & $\mathrm{Fe}$ \\
6 & - & $\mathrm{Se}$ & $\mathrm{W}$ & - & $\mathrm{Ni}$ & - \\
7 & - & - & $\mathrm{W}$ & $\mathrm{Mo}$ & $\mathrm{Ni}$ & - \\
8 & - & $\mathrm{Se}$ & - & $\mathrm{Mo}$ & $\mathrm{Ni}$ & $\mathrm{Fe}$ \\
9 & $\mathrm{Co}$ & - & $\mathrm{W}$ & - & - & - \\
10 & $\mathrm{Co}$ & $\mathrm{Se}$ & - & - & - & $\mathrm{Fe}$ \\
11 & $\mathrm{Co}$ & - & - & $\mathrm{Mo}$ & - & $\mathrm{Fe}$ \\
12 & $\mathrm{Co}$ & $\mathrm{Se}$ & $\mathrm{W}$ & $\mathrm{Mo}$ & - & - \\
13 & $\mathrm{Co}$ & - & $\mathrm{W}$ & - & $\mathrm{Ni}$ & $\mathrm{Fe}$
\end{tabular}




\begin{tabular}{lllllll}
14 & Co & Se & - & - & $\mathrm{Ni}$ & - \\
15 & Co & - & - & Mo & Ni & - \\
16 & Co & Se & W & Mo & Ni & Fe \\
\hline
\end{tabular}


Table 2. Existing and additional concentration of trace elements in digesters at the start of the semi-continuous trials

\begin{tabular}{|c|c|c|c|}
\hline \multirow[b]{2}{*}{ Element } & \multirow[b]{2}{*}{ Compound used } & \multicolumn{2}{|c|}{ Element concentration $\left(\mathrm{mg} \mathrm{l}^{-1}\right)$} \\
\hline & & $\begin{array}{l}\text { Trace element } \\
\text { concentration in the } \\
\text { inoculum digestate }\end{array}$ & $\begin{array}{l}\text { Initial trace element } \\
\text { addition made on day } \\
1\end{array}$ \\
\hline Aluminium (Al) & $\mathrm{AlCl}_{3} \cdot 6 \mathrm{H}_{2} \mathrm{O}$ & 63.3 & 0.1 \\
\hline Boron (B) & $\mathrm{H}_{3} \mathrm{BO}_{3}$ & 2.5 & 0.1 \\
\hline Cobalt (Co) & $\mathrm{CoCl}_{2} \cdot 6 \mathrm{H}_{2} \mathrm{O}$ & 0.083 & 1 \\
\hline Copper $(\mathrm{Cu})$ & $\mathrm{CuCl}_{2} \cdot 2 \mathrm{H}_{2} \mathrm{O}$ & 5.75 & 0.1 \\
\hline Iron $(\mathrm{Fe})$ & $\mathrm{FeCl}_{2} \cdot 4 \mathrm{H}_{2} \mathrm{O}$ & 173.7 & 5 \\
\hline Manganese (Mn) & $\mathrm{MnCl}_{2} \cdot 4 \mathrm{H}_{2} \mathrm{O}$ & 18.5 & 1 \\
\hline Molybdenum (Mo) & $\left(\mathrm{NH}_{4}\right)_{6} \mathrm{Mo}_{7} \mathrm{O}_{24} \cdot 4 \mathrm{H}_{2} \mathrm{O}$ & 0.29 & 0.2 \\
\hline Nickel (Ni) & $\mathrm{NiCl}_{2} \cdot 6 \mathrm{H}_{2} \mathrm{O}$ & 2.9 & 1 \\
\hline Selenium (Se) & $\mathrm{Na}_{2} \mathrm{SeO}_{3}$ & 0.05 & 0.2 \\
\hline Tungsten (W) & $\mathrm{Na}_{2} \mathrm{WO}_{4} \cdot 2 \mathrm{H}_{2} \mathrm{O}$ & $<0.035$ & 0.2 \\
\hline Zinc (Zn) & $\mathrm{ZnCl}_{2}$ & 8.11 & 0.2 \\
\hline
\end{tabular}

Table 3 Oligonucleotide probes used with target groups

\begin{tabular}{llll}
\hline Probe name & Target group & Probe sequence (5'-3') & $\begin{array}{l}\text { Fluoro- } \\
\text { chrome }\end{array}$ \\
\hline EUB338 & Bacteria (most) & GCTGCCTCCCGTAGGAGT & Cy5 \\
EUB338+ & Bacteria (remaining) & GCWGCCACCCGTAGGTGT & Cy5 \\
ARC915 & Archaea & GTGCTCCCCGCCAATTCC & 6-Fam \\
MX825 & Methanosaetaceae & TCGCACCGTGGCCGACACCTAGC & Cy3 \\
MS1414 & Methanosarcinaceae & CTCACCCATACCTCACTCGGG & Cy3 \\
hMS1395 & MS1414-helper & GGTTTGACGGGCGGTGTG & - \\
hMS1480 & MS1414-helper & CGACTTAACCCCCCTTGC & - \\
MSMX860 & Methanosarcinales & GGCTCGCTTCACGGCTTCCCT & Cy5 \\
MG1200 & Methanomicrobiales & CGGATAATTCGGGGCATGCTG & Cy3 \\
MB1174 & Methanobacteriales & TACCGTCGTCCACTCCTTCCTC & Cy3 \\
MC1109 & Methanococcales & GCAACATAGGGCACGGGTCT & Cy3 \\
\hline Note: W, A+T mixed base. & &
\end{tabular}

Note: W, A+T mixed base. 
Table 4. Characteristics of the inoculum digestate at the start of the semi-continuous fed trial and the average composition of the food waste used over the trial period.

\begin{tabular}{|c|c|c|}
\hline & Digestate & Food waste \\
\hline $\mathrm{pH}$ & 8.0 & $4.71 \pm 0.01(1: 5)$ \\
\hline TS (\% of fresh matter) & 6.34 & $23.74 \pm 0.08$ \\
\hline VS (\% of fresh matter) & 4.59 & $21.71 \pm 0.09$ \\
\hline VS (\% of TS) & 72.4 & $91.44 \pm 0.39$ \\
\hline \multicolumn{3}{|l|}{ Trace elements ( $\mathrm{mg} \mathrm{kg}^{-1}$ fresh matter) } \\
\hline Aluminium $(\mathrm{Al})$ & 63.3 & \\
\hline Boron (B) & 2.5 & \\
\hline Cobalt (Co) & 0.083 & $<0.060$ \\
\hline Copper $(\mathrm{Cu})$ & 5.75 & $1.7 \pm 0.2$ \\
\hline Iron $(\mathrm{Fe})$ & 173.7 & 54 \\
\hline Manganese (Mn) & 18.5 & $20 \pm 3$ \\
\hline Molybdenum (Mo) & 0.29 & $0.11 \pm 0.01$ \\
\hline Nickel (Ni) & 2.9 & $1.7 \pm 0.7$ \\
\hline Selenium $(\mathrm{Se})$ & 0.050 & $<0.070$ \\
\hline Tungsten (W) & $<0.035$ & $<0.25$ \\
\hline Zinc $(\mathrm{Zn})$ & 8.11 & $7.8 \pm 2.6$ \\
\hline \multicolumn{3}{|c|}{ Potentially toxic element ( $\mathrm{g} \mathrm{kg}^{-1}$ fresh matter) } \\
\hline Cadmium $(\mathrm{Cd})$ & 0.038 & $<0.25$ \\
\hline Chromium (Cr) & 5.25 & $6.9 \pm 0.3$ \\
\hline Lead $(\mathrm{Pb})$ & 0.63 & $<2.5$ \\
\hline Mercury $(\mathrm{Hg})$ & $<0.010$ & $<0.003$ \\
\hline \multicolumn{3}{|l|}{ Miacro nutrients ( $\mathrm{g} \mathrm{kg} g^{-1}$ fresh matter) } \\
\hline Calcium $(\mathrm{Ca})$ & 2.16 & \\
\hline Magnesium (Mg) & 0.168 & \\
\hline Potassium $(\mathrm{K})$ & 2.63 & $3.39 \pm 0.19$ \\
\hline Sodium $(\mathrm{Na})$ & 1.13 & \\
\hline Phosphorus (P) & 0.700 & $1.28 \pm 0.08$ \\
\hline Total Kjeldahl nitrogen $(\mathrm{N})$ & 8.47 & $8.12 \pm 0.01$ \\
\hline \multicolumn{3}{|c|}{ Other digestate parameters ( $\mathrm{g} \mathrm{kg}^{-1}$ fresh matter) } \\
\hline Total ammoniacal nitrogen $\left(\mathrm{NH}_{3}-\mathrm{N}\right)$ & 4.7 & \\
\hline Total volatile fatty acid & 4.4 & \\
\hline Acetic acid & 4.1 & \\
\hline Propionic acid & 0.1 & \\
\hline
\end{tabular}




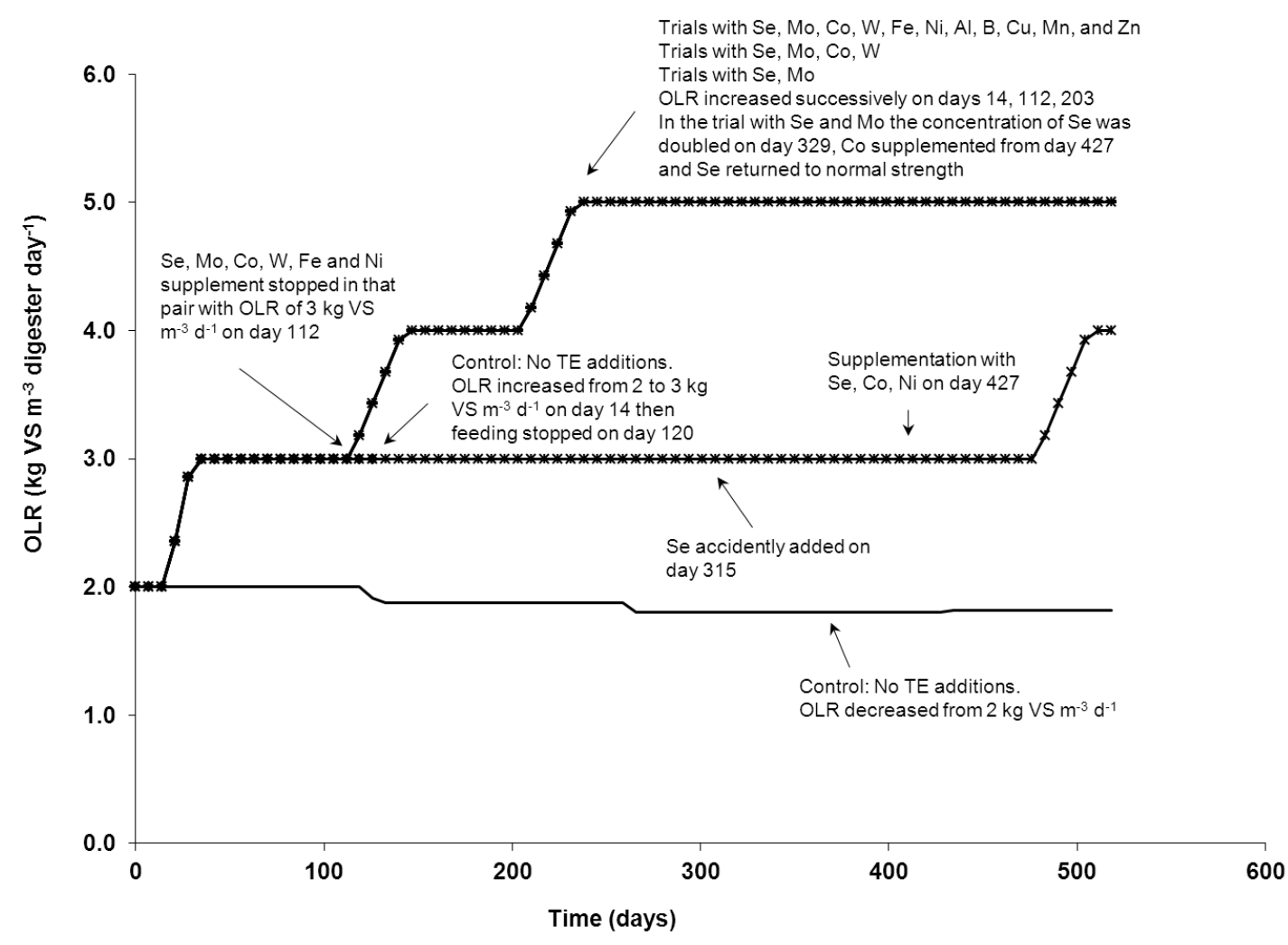

Fig. 1. Digester feeding regime, interventions and changes over the trial period
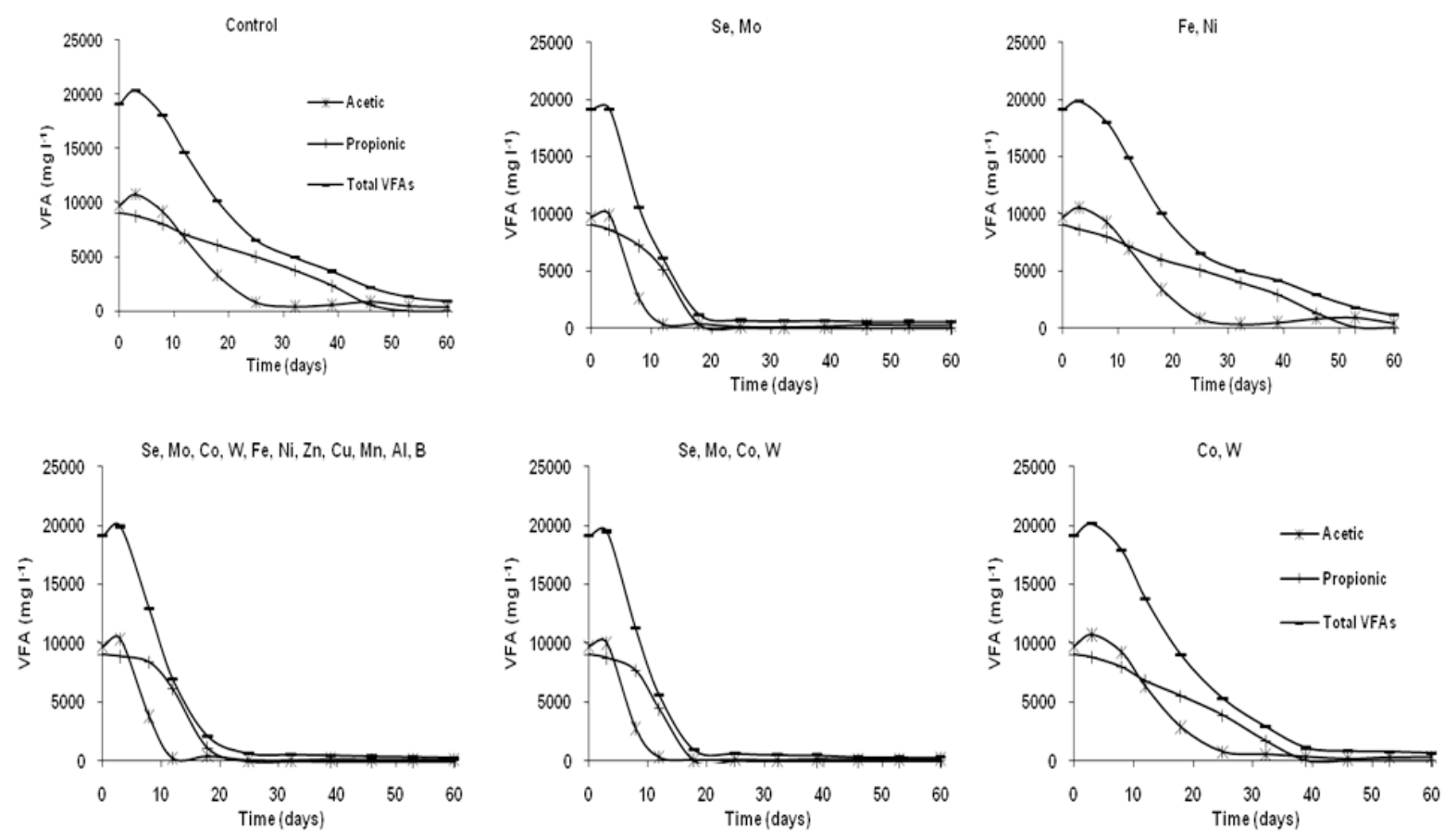

Fig. 2. Selected VFA degradation profiles in control and TE supplemented flasks 

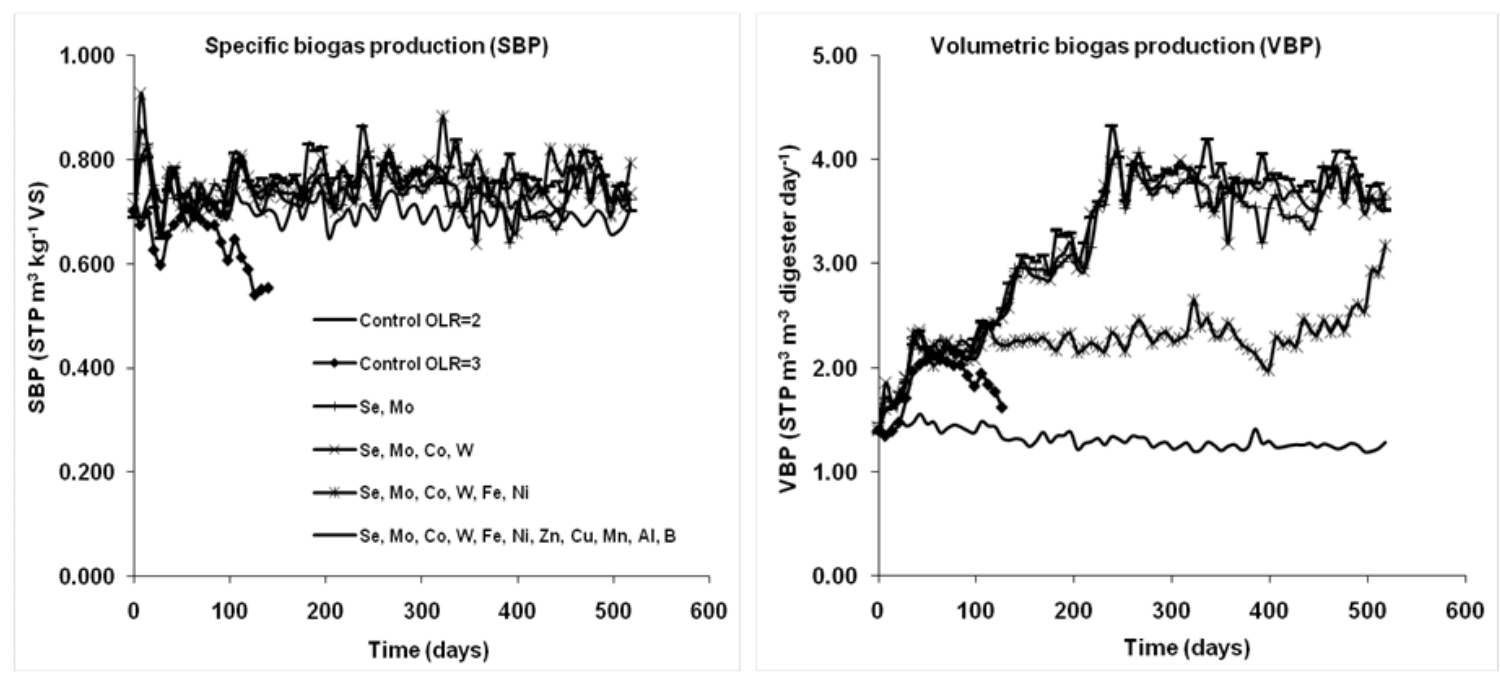

Fig. 3. Specific and volumetric biogas production in control and TE supplemented digesters (values are weekly averages of duplicate digesters, and showed $<5 \%$ difference between them).
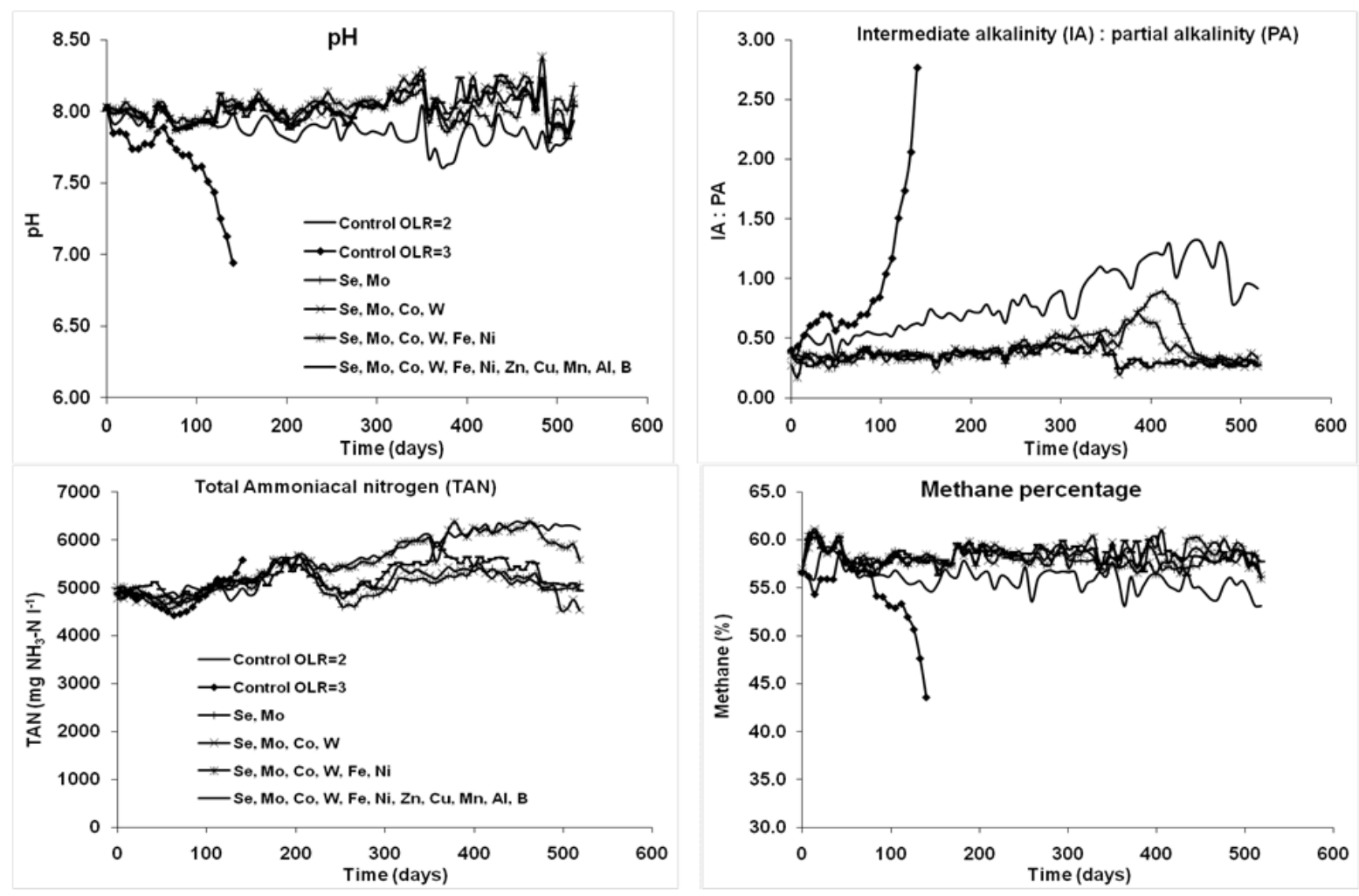

Fig. 4. pH, alkalinity, ammonia and biogas methane percentage in control and TE supplemented digesters 


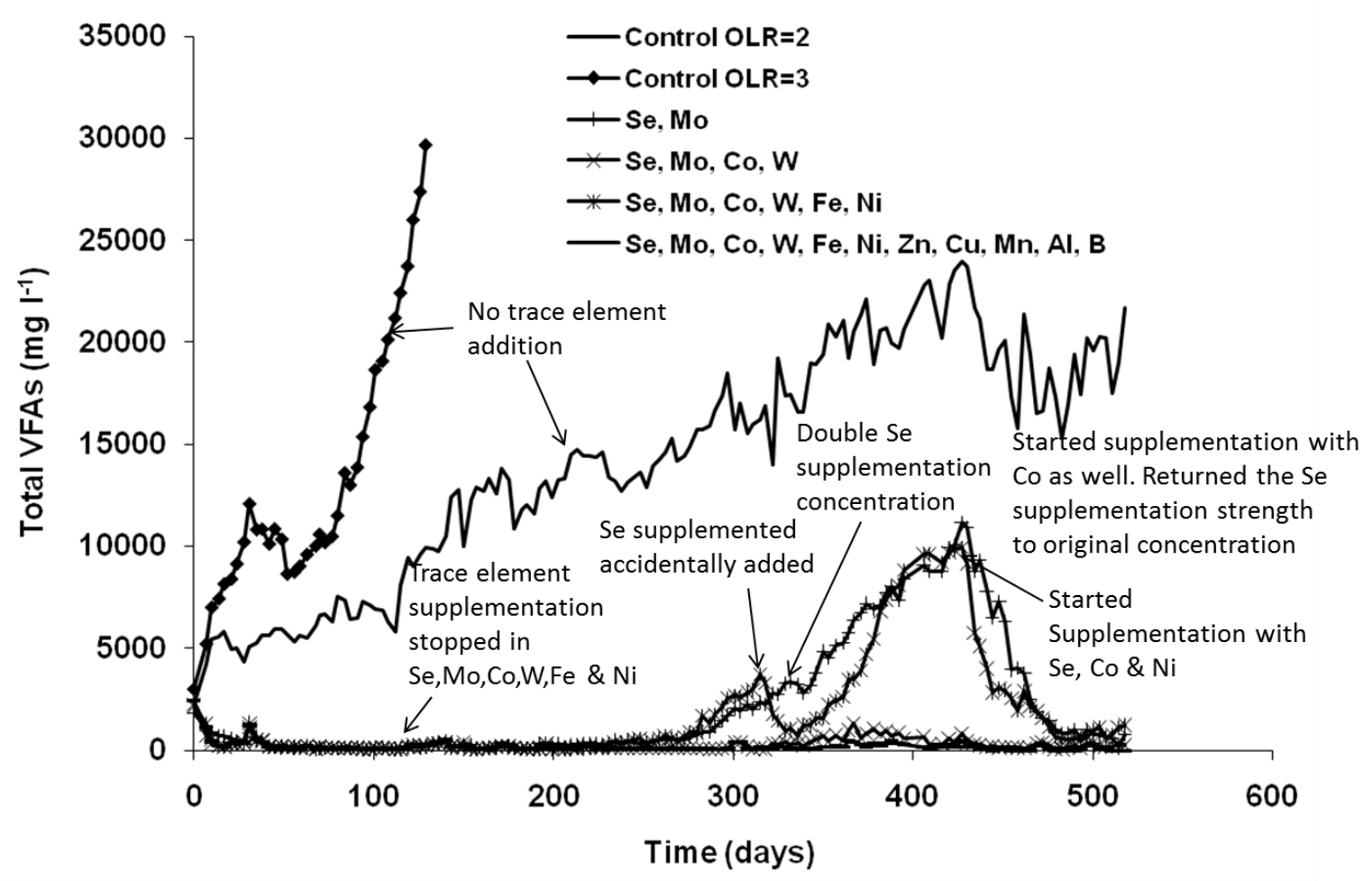

Fig. 5. Total VFA concentrations (g) in control and TE supplemented digesters
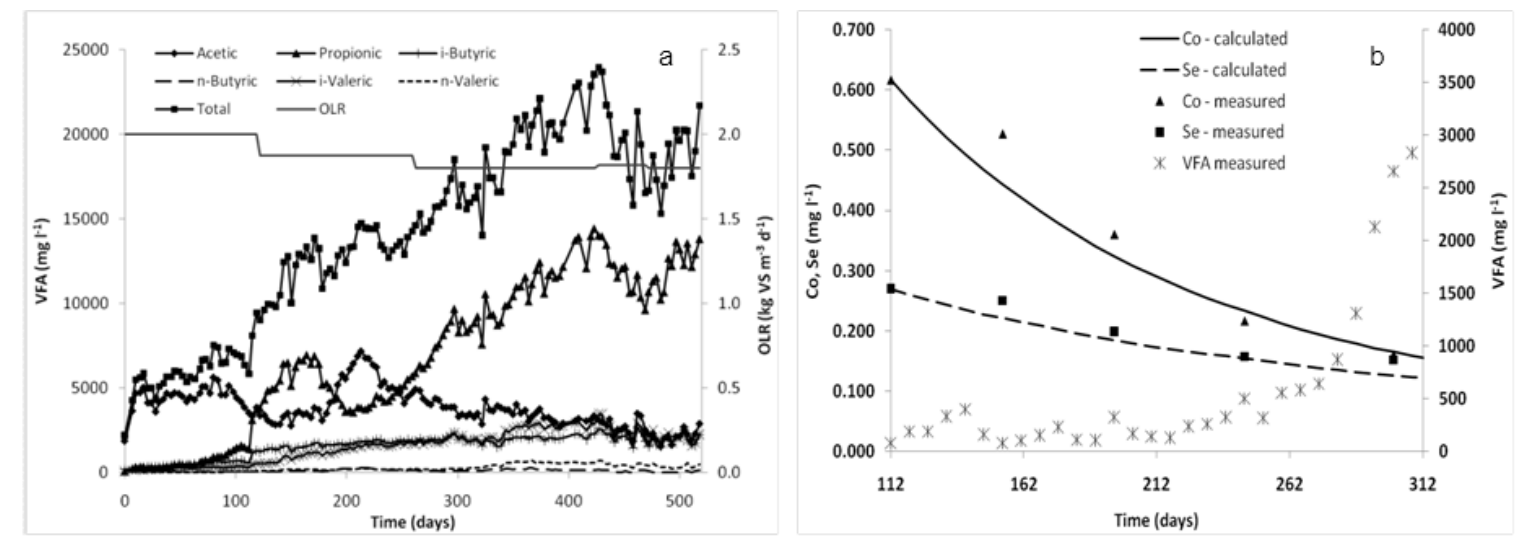

Fig. 6. VFA profiles and measured and calculated TE concentrations: a) Measured and calculated Se and Co concentrations and total VFA in digester after cessation of TE

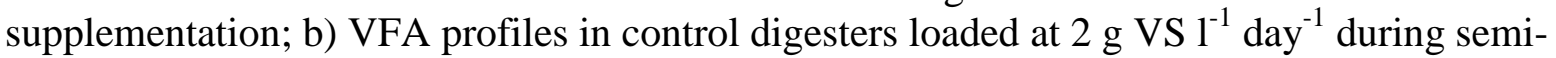
continuous trial. 